$\begin{gathered}\text { Revista do Departamento de Geografia } \\ \text { Universidade de São Paulo } \\ \text { www.revistas.usp.br/rdg } \\ \text { Revista do Departamento de Geografia USP }\end{gathered}$
ISSN 2236-2878

\title{
ESTIMATIVA DA POLUIÇÃO VEICULAR E QUALIDADE DO AR NAS PRINCIPAIS VIAS DO SISTEMA VIÁRIO DA REGIÃO CENTRAL DA CIDADE DE JUIZ DE FORA - MG
}

\section{ESTIMATED VEHICLE POLLUTION AND AIR QUALITY IN THE MAIN ROADS OF THE ROAD SYSTEM OF THE CENTRAL CITY OF JUIZ DE FORA - MG}

Cássia Castro Martins Ferreira

Universidade Federal de Juiz de Fora cassia.castro@ufjf.edu.br

Daiane Evangelista Oliveira

Universidade Federal de Juiz de Fora daiane.evangelista.oliveira@gmail.com

Recebido (Received): 15/07/2016

Aceito (Accepted): 04/10/2016

DOI: $10.11606 /$ rdg.v0i0.117682

Resumo: Os aumentos da população urbana vêm requerendo um crescente processo de mobilidade, porém vem se privilegiando os automóveis, aumentando sobremaneira o número de carros nas ruas e a consequente poluição atmosférica. Tornando vital para o controle da poluição do ar e visando a melhoria da qualidade de vida urbana torna-se fundamental deter o controle, monitoramento e estabelecer medidas para que a poluição do ar não se agrave. Desta forma, o presente artigo aplica para as principais vias do sistema viário da área central da cidade de Juiz de Fora, uma metodologia proposta por Taco (2006) e Filizola (2005) de estimativa da poluição veicular, permitindo conhecer a quantidade de $\mathrm{CO}$ e $\mathrm{NOx} / \mathrm{g} / \mathrm{km} / \mathrm{h}$. Os valores estimados permitiram criar cenários dos níveis de emissão veicular na área de estudo. Além disso, foi estabelecido uma série de mapeamentos temáticos da área de estudo afim de avaliar a contribuição do espaço urbano nos processos de dispersão/concentração da poluição nos diferentes pontos de contagem veicular. Por fim foi verificada a relação entre os valores estimados e o Índice de qualidade do ar (CETESB, 2013), no qual detecta-se que as piores condições de poluição atmosférica estão presentes nas vias mais estreitas e com acentuado fluxo de veículos.

Palavras-chave: Poluição do ar; Poluição veicular; Qualidade do ar.

\begin{abstract}
The increase in urban population has a growing process requiring mobility, but has been focusing on the car, greatly increasing the number of cars on the streets and the resulting air pollution. Making it vital for the control of air pollution and aiming to improve the quality of urban life it is essential to retain control, monitoring and establish measures to ensure that air pollution does not deteriorate. Thus, this article applies to the main routes of the road system of the central area of the city of Juiz de Fora, a methodology proposed by Taco (2006) and Filizola (2005) of vehicular pollution estimate, allowing know the amount of $\mathrm{CO}$ and NOx / $g / \mathrm{km} / \mathrm{h}$. The estimated values have created scenarios of vehicle emission levels in the study area. In addition, a series of thematic maps of the study area was established in order to assess the contribution of urban space in dispersal processes / concentration of pollution in different parts of car count. Finally it verified the relationship between the estimated and the air quality index (CETESB, 2013), which is detected that the worst conditions of air pollution are present in the most narrow roads and elevate traffic flow.
\end{abstract}

Keywords: Air pollution; Vehicular pollution; Air quality 


\section{INTRODUÇÃO}

O aumento da população urbana que o mundo todo vem enfrentando, pode provocar o acréscimo de tensões sobre o espaço, ecossistemas, infraestruturas, instalações e estilos de vida pessoais, o que vem refletindo na qualidade de vida desta população. O aumento da necessidade de mobilidade e consequente incremento da circulação rodoviária têm ocasionado uma elevação significativa no volume de gases provenientes da queima de combustíveis fósseis, sejam eles atrelados a veículos pessoais movidos a gasolina/álcool ou aqueles que dependem do óleo diesel.

Nas áreas urbanas as fontes antropogênicas típicas da poluição do ar são principalmente o tráfego rodoviário e, quando existente, a atividade industrial.

Portanto, o crescimento contínuo do número de veículos que circula nas vias de tráfego das cidades podem gerar impactos negativos, tais como congestionamentos, acidentes de trânsito, degradação da paisagem, degradação da qualidade de vida, utilização de espaços públicos prioritariamente por veículos, desconforto geral no uso dos espaços públicos pelo pedestre, poluição sonora e poluição atmosférica (CRUZ, 2006).

Conforme os dados apresentados pelo Inventário Nacional de Emissões Atmosféricas por Veículos Automotores Rodoviários (BRASIL, 2013), no Brasil vem aumentando desde 1980, sendo que entre 2009 e 2012, a frota de veículos teve um aumento de 27\%. O volume de veículos no Brasil atingiu aproximadamente 49 milhões em 2012, destes 57\% são de automóveis, 28\% são de motocicletas, $11 \%$ são de veículos comerciais leves, $3 \%$ são de caminhões e $1 \%$ a ônibus.

Em Minas Gerais, a situação não é diferente, apresentando um expressivo aumento no número de veículos desde 2002.

A frota de ônibus indica um menor crescimento, repercutindo numa tendência cada vez maior da população urbana fazer uso do transporte individual e numa falta de investimento em uma das modalidades de transporte público coletivo.

Outro dado relevante, diz respeito ao ano de fabricação do veículo, pois está atrelado ao fator de emissão, uma vez que a quantidade de poluentes emitida corresponde aos critérios e legislação vigente quando o veículo foi fabricado.

Segundo a FEAM (2014) a frota mais antiga é a de veículos pesados, no qual 36\% apresentam ano de fabricação anterior a 1988. Com relação aos ônibus $46 \%$ teve seu ano de fabricação anterior a 2000. Os automóveis 28\% foram fabricados entre 2009 e 2013 e as motocicletas 33\% foram fabricadas entre 2005 e 2008. No Plano de Controle de Poluição Veicular do Estado de São Paulo (CETESB, 2011) destaca que ao longo da vida útil do veículo ocorra um incremento da emissão de poluentes por quilômetro rodado, considerando que a deterioração das emissões varia conforme o modelo e o poluente. AZUAGA (2000) enfatiza que as emissões de hidrocarbonetos (HC) e monóxido de carbono (CO) tendem a crescer com o uso do veículo, mesmo que este apresente uma manutenção frequente. Pois ainda assim, ocorre o desgaste de peças e componentes, que afetam o motor e consequentemente sua capacidade de processar. Segundo Dutra (2007) em um estudo com a frota de automóveis em Belo Horizonte-MG, em um período de 10 anos, os veículos de Belo Horizonte, aumentaram sua emissão em média $26 \%$ para o $\mathrm{CO}$ e de $45 \%$ de HC do que quando estes veículos foram produzidos.

Juiz de Fora é a quarta cidade do estado de Minas Gerais com maior frota de veículos, tendo em 2015 um total de 242.273 veículos, sendo que destes 163.820 são automóveis. No período de 2005 a 2015 a frota de veículos na cidade cresceu $195,8 \%$, sendo que a frota de automóveis teve um crescimento de $179,1 \%$ (Gráfico 1).

Foi possível constatar que a emissão de gases poluentes hidrocarbonetos, monóxido de carbono e óxidos de nitrogênio (NOx) é influenciada diretamente pelo tamanho da frota do município. Segundo a ECOSOFT (2003) apud FEAM 2014 no inventário de emissão de poluentes atmosféricos realizados em Belo Horizonte, Betim e Contagem, detectou-se uma enorme participação da frota veicular nos totais de poluentes emitidos no município, sendo que em Belo Horizonte a frota de veículos é responsável por aproximadamente 95\% dos poluentes (PM10 e NOx). Em Contagem a poluição veicular atinge o percentual de 76 de PTS, CO e compostos orgânicos voláteis (VOC). Em Betim com relação a poluição veicular, os níveis ficam acima de $81 \%$ para CO e VOC. 
Gráfico 1: Progressão da frota total de veículos e automóveis (unidades) em Juiz de Fora-MG, entre 2005 e 2015.

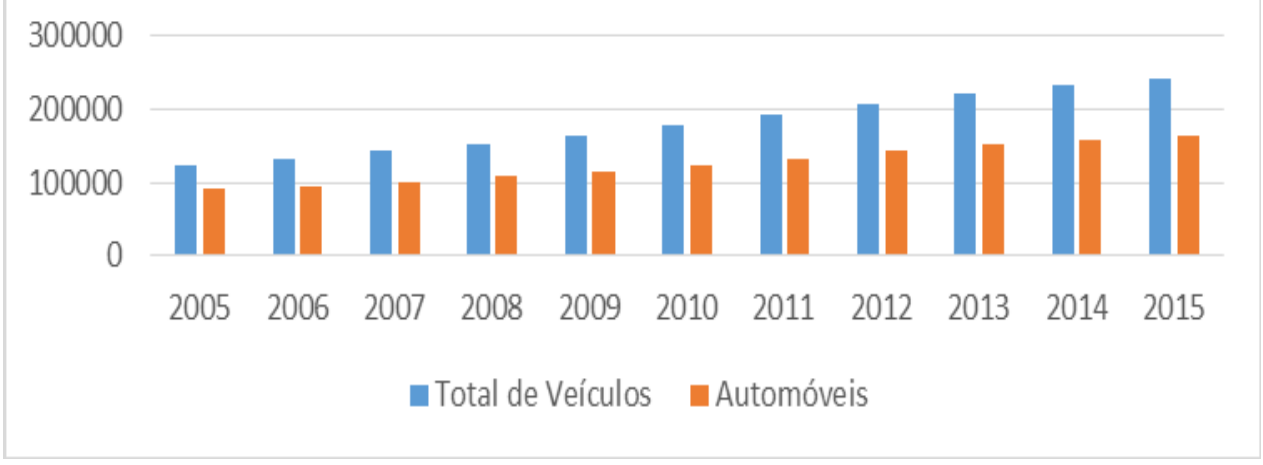

Fonte: DENATRAN, 2016

Dados alarmantes também são encontrados na Europa, Goodwin et al. (2001) mostra que no reino Unido a contribuição média do tráfego de automóveis para a poluição atmosférica é de aproximadamente 78\% para o CO2, de 83\% de PM10, 55\% de NOx. Segundo Ferraz e Motta (2008) em áreas que apresentam alto fluxo de tráfego, principalmente de veículos pesados, estas percentagens ficam ainda mais alarmantes. $\mathrm{O}$ número elevado de veículos provoca a diminuição da velocidade média de percurso, acarretando aumento da emissão de gases, para a mesma quilometragem percorrida.

A poluição veicular contribui com $72 \%$ da poluição do ar nas cidades urbanas quando comparadas à poluição oriunda de domésticas (8\%) e industriais (20\%), de acordo com o Central Pollution Control Board (CPCB 2012). Dentro centros das cidades e ruas congestionadas, o tráfego é responsável por $80 \%$ a $90 \%$ destes poluentes e esta situação é particularmente grave em cidades de países em desenvolvimento (WHITELEGG e HAQ, 2003; BATTERMAN et al. 2014). As tendências recentes indicam que os veículos rodoviários são responsáveis por $74 \%$ das NOX e $94 \%$ das emissões de fumaça preta em Londres (USEPA, 2010). De acordo com a United Agência de Proteção Ambiental dos Estados (USEPA, 2010), veículos a diesel são responsáveis por $32 \%$ e $87 \%$ do total de emissões para esses dois poluentes respectivamente. Da mesma forma, devido ao rápido aumento no número de veículos, as emissões dos veículos já se tornaram uma grande preocupação ambiental na China (HUO et al., 2011). Na Indonésia, 70\% da poluição do ar é devido à atividade de transporte e $30 \%$ vem da atividade industrial (SUTANTO et al. 2005).

Logo, o estudo das condições, distribuição, espacialização e situações reais que influenciam na dispersão/concentração das emissões veiculares faz-se necessário para, assim, estabelecer regras de gestão e controle da emissão de poluentes veiculares.

Analisando as frequentes e contínuas transformações do ambiente pela sociedade e estabelecendo uma visão integrada entre o homem e a natureza, Monteiro (1976) desenvolveu um método de análise do sistema Clima Urbano

No qual destaca que "a estrutura interna do S.C.U. não pode ser definida pela simples superposição ou adição de suas partes (compartimentação ecológica, morfológica, ou funcional urbana), mas somente por meio da íntima conexão entre elas" (MONTEIRO, 1976, p. 99). Subdivide o sistema em três canais de percepção humana o canal do conforto térmico (Subsistema Termodinâmico), o canal da qualidade do ar (Subsistema Físico-Químico) e o canal do impacto meteórico (Subsistema Hidromecânico).

Neste artigo trabalharemos especificamente com a poluição atmosférica, Monteiro (1976) discute-a no segundo canal, denominado de Qualidade do ar. Essa discussão é pautada nos aspectos físico-químicos do ar urbano e destaca a delicada questão da qualidade do ar de um ambiente de cidade. $\mathrm{O}$ autor entende esse canal como sendo uma responsabilidade humana. Destacando nesta abordagem como se procede a dispersão de poluentes diante da realidade das cidades brasileiras, ressaltando o trânsito intenso de veículos, associados ao ambiente densamente construído. Destacando a importante função dos veículos automotores, já evidenciada por Monteiro em 1976, este trabalho enfocará na discussão, estimativa da poluição veicular em uma cidade média. Desta forma o objetivo principal deste trabalho é identificar espacialmente os níveis de emissão de gases derivados de veículos automotores nas áreas urbanas por meio dos fluxos veiculares nas vias. 


\section{POLUIÇÃO VEICULAR}

Dentre os principais poluentes nocivos à saúde, têm-se o monóxido de carbono (CO), os hidrocarbonetos (HC), os materiais particulados, os óxidos de Nitrogênio (NOx) e os óxidos de enxofre (SOx). A emissão de poluentes por veículos automotores é a principal responsável pela degradação da qualidade do ar nos centros urbanos (DUTRA, 2007).

Ocorrem no motor reações químicas associadas ao processo de combustão, e, através do tubo de escapamento dos veículos são emitidos poluentes, tais como: monóxido de carbono, hidrocarbonetos, óxidos de nitrogênio, óxidos de enxofre, ácidos orgânicos e material particulado. Este último, devido ao seu tamanho microscópico, às suas propriedades químicas, e à sua persistência na atmosfera, pode se constituir em riscos graves à saúde pública, que variam desde irritação nos olhos a problemas respiratórios, causando custos diretos e indiretos para a sociedade.

A poluição atmosférica está relacionada a três etapas, se iniciando com a emissão de poluentes por fontes antropogênicas ou naturais, uma vez que este poluente se encontra na atmosfera inicia-se o processo de dispersão, no qual é transportado pelos movimentos do ar, precipitações, massas de ar, etc. A interação entre os gases poluentes e a atmosfera definirá o grau de qualidade do ar. Isto é, quanto maior a concentração de um ou mais poluentes na atmosfera pior será a qualidade do ar. Logo, considerando uma fonte emissora contínua, dependerá das características da atmosfera em dissipar ou concentrar mais a poluição (AZUAGA, 2000). Na atmosfera, a poluição é o resultado do desequilíbrio entre a emissão e a capacidade da atmosfera em dispersar os poluentes (TACO, 2006).

Segundo Taco (2006), Martins (1998) a dispersão dos poluentes sofre interferência de diversos fatores relacionados ao ambiente construído, tais como tipos de construção, obstáculos que margeiam as vias, layout, rugosidade e porosidade da superfície, porosidade das edificações, verticalidade das edificações, arborização viária e canyons urbanos. A dispersão também é influenciada pela topografia e as condições meteorológicas (direção e velocidade dos ventos, chuvas, o grau de estabilidade da atmosfera (velocidade dos ventos e variação vertical da temperatura do ar com a altitude) determinando a capacidade do poluente em expandir-se verticalmente na atmosfera. Desta forma, a concentração de poluentes na atmosfera é determinada pelas condições atmosféricas e sua capacidade de dispersão e pelas características de emissão inicial.

Segundo Martins (1999), a poluição está ainda relacionada a três fatores, a saber: intensidade, continuidade e efetividade. Sendo que a intensidade se define pela quantidade de poluente em uma amostra de ar numa dada região; a continuidade é o período de tempo pelo qual os poluentes permanecem na composição do ar e; a efetividade é o efeito negativo dos poluentes sobre o ambiente.

As emissões veiculares variam em função das características dos veículos (tipo do motor, estado de conservação e idade do veículo, regulagem e manutenção do veículo), além do tipo de combustível, frota circulante, modo de operação do veículo, características do tráfego e as características climáticas.

Os principais poluentes emitidos diretamente pelos veículos automotores são: o monóxido de carbono (CO), os hidrocarbonetos (HC), os óxidos de nitrogênio (NOx), os óxidos de enxofre (SOx), o material particulado (MP) (partículas totais em suspensão, fumaça, partículas inaláveis e partículas inaláveis finas) e os aldeídos.

Para Monteiro (2008) os dados presentes na Tabela 1, confirma a premissa de que as condições de congestionamento de tráfego são críticas para a emissão de poluentes em geral. As maiores emissões são as de $\mathrm{CO}$, que ocorrem quando os veículos estão parados, com o motor acionado. A condição que menos emite poluentes é quando o motor opera à velocidade constante. Entre as exceções estão o NOx, que apresenta o segundo maior grau de emissão nesta condição. Para os veículos a diesel, observa-se que as maiores emissões estão nos HCs e NOx.

Nesta pesquisa propomos trabalhar com o CO e NOx. Pois o CO é encontrado em altos níveis nas regiões com um intenso trânsito de veículos (DENATRAN, 2016). O monóxido de Carbono (CO) é formado em grande quantidade nas altas temperaturas produzidas no início do processo de combustão, oxidando-se nos processos subsequentes de expansão e resfriamento, formando o dióxido de carbono (CO2). O NO é produzido no processo de combustão pela oxidação de $\mathrm{N} 2$ do ar pelo $\mathrm{O} 2$. A reação $\mathrm{N} 2+\mathrm{O} 2=2 \mathrm{NO}$ é mais favorável em altas temperaturas e, por isto, sua produção está mais relacionada a motores de veículos pesados (Sala, 1999). Os automóveis também produzem NO, quando alcançam alta velocidade. Os NOx contribuem para a formação do smog fotoquímico devido à sua reação com alguns grupos de hidrocarbonetos, ocasionando a redução de visibilidade nas vias. Os óxidos de nitrogênio resultam da 
combinação do oxigênio e do nitrogênio presentes no ar admitido pelo motor em condições de alta temperatura e pressão (DENATRAN, 1980).

Tabela 1: Composição dos gases de exaustão de veículos automotores ${ }^{1}$.

\begin{tabular}{ccccc}
\hline \multirow{2}{*}{ Poluente } & \multicolumn{4}{c}{ Modo de Operação } \\
\cline { 2 - 5 } & Ponto Morto & Acelerando & $\begin{array}{c}\text { Velocidade } \\
\text { Constante }\end{array}$ & Desacelerando \\
\hline CO & 100 & Gasolina & \\
\hline HC & 7,7 & 42 & 39 & 14 \\
NO $_{\mathbf{x}}$ & 0,04 & 2,3 & 1,4 & 0,03 \\
\hline $\mathbf{C O}$ & - & 1,4 & 0,9 & - \\
HC & 0,6 & Diesel & & 0,4 \\
NO & 0,09 & 0,3 & 0,15 & 0,04 \\
\hline
\end{tabular}

Fonte: Monteiro (2008).

Vários são os trabalhos que enfatizam o uso do Sistema de Informações Geográficas no monitoramento da qualidade do ar, associado a modelos de superfície, de poluição do ar e modelos de dispersão (KUMAR, et al., 2015; MAANTAY et.al., 2008, FISCHER et.al., 2005; MATEJICEK L., 2005; RIBEIRO E DOMINGUEZ, 2005).

Outros estabeleceram por meio do Sistema de Informações Geográficas metodologias para avaliar a qualidade do ar em função das características de tráfego (SOULEYRETTE et al., 1992; BRUCKMAN et al., 2003; MEDINA et al., 1994; PANDEY et al., 2013). O uso de modelos matemáticos aplicados à dinâmica atmosférica associados à estrutura SIG foram desenvolvidos por Jensen et al. (2001); Kousa et al., 2002; Gualtieri e Tartaglia, 1998; Maantay et al., 2008.

\section{METODOLOGIA}

A metodologia seguirá cinco etapas distintas, no qual a primeira etapa consistiu na delimitação da área de aplicação do modelo. A segunda na caracterização, quantificação e levantamento dos dados relativos ao fluxo de veículos nas principais vias da área central da cidade de Juiz de Fora. A terceira consistiu na quantificação da emissão veicular. A quarta etapa envolveu todo o processo de espacialização dos dados e informações relativos ao ambiente construído, aos aspectos topográficos, de fluxo de veículos e de emissão de poluentes veicular. A quinta etapa abordou a relação entre o índice de qualidade do ar proposto pela CETESB (2013) e os dados estimados de CO e NOx. A metodologia seguiu parcialmente os parâmetros propostos por Taco (2006).

\section{A CIDADE, SEU SÍTIO E O CLIMA URBANO}

A cidade de Juiz de Fora está localizada na Zona da Mata Mineira. A morfogênese levou a duas principais formas de relevo, sendo estas os terraços fluviais e as elevações. As características do relevo desempenharam uma função significativa no processo de expansão da malha urbana (Figura 1), inicialmente a cidade é assentada ao longo do vale do rio Paraibuna e de seus afluentes, em função da baixa declividade. O que levou a uma direção geral do processo de ocupação, no sentido do rio Paraibuna, que segue na direção NW-SE, com altitudes entre 600 e 990m. As áreas com altitudes maiores que $900 \mathrm{~m}$, estão localizadas principalmente na porção nordeste da cidade e estão atreladas às planícies alveolares, com grande ocupação demográfica, sendo ainda, consideradas áreas de expansão urbana, como a porção oeste e nordeste da cidade (FERREIRA, 2014).

\footnotetext{
${ }^{1}$ Os valores estão representados por índices, no qual o índice 100 significa uma composição de 69.000 ppm de CO quando um veículo a gasolina está em ponto morto. 


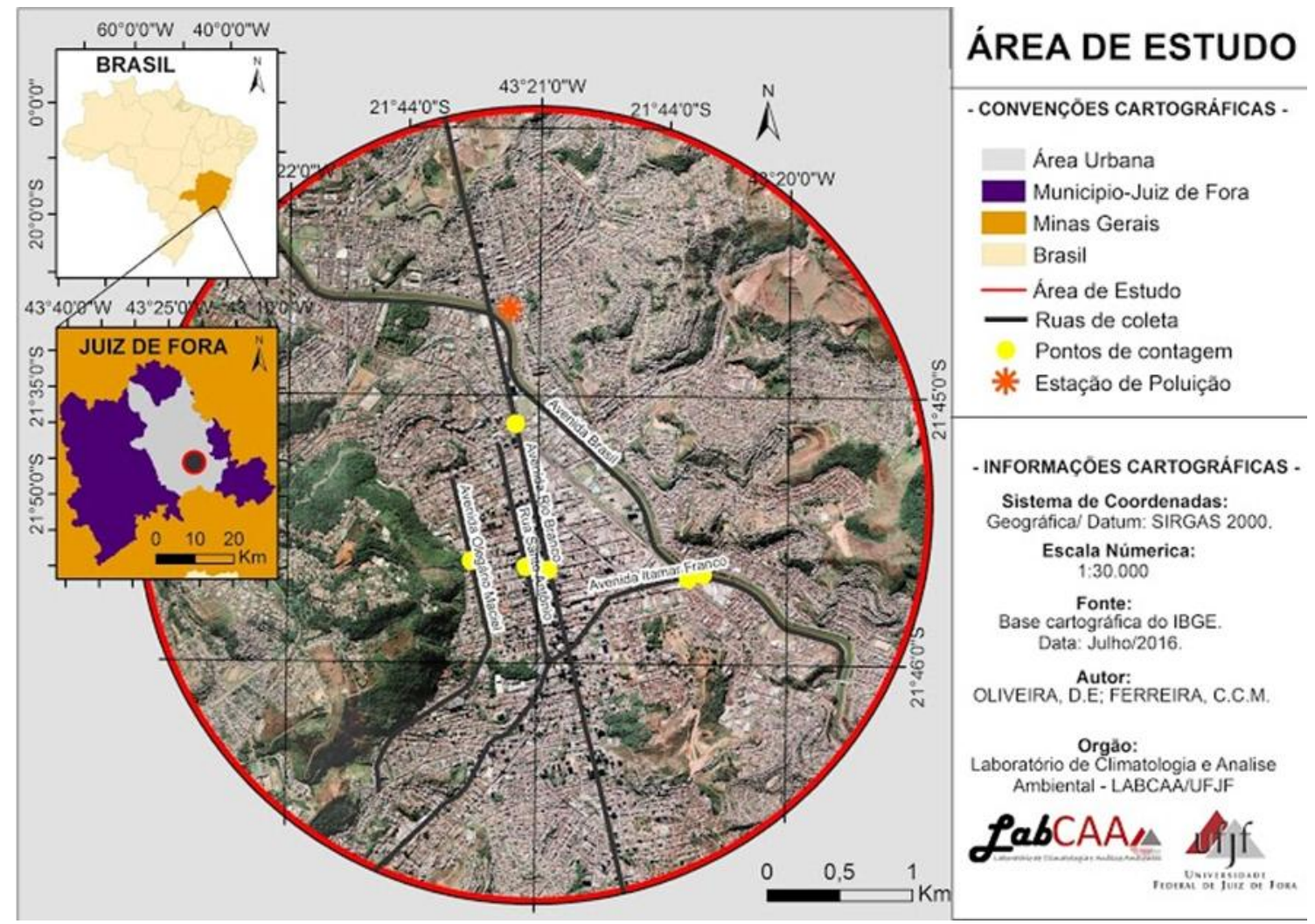

Figura 1: Área de Estudo - Juiz de Fora - MG.

O núcleo central da cidade aproveitando-se desta condição natural alojou-se na seção alargada do vale do rio Paraibuna, estrangulada por uma barra resistente, à jusante (PJF, 1996).

O sítio urbano da cidade de Juiz de Fora, seja pela diferença altimétrica, que em alguns pontos chega a 300m, ou pela forma e estrutura urbana, apresenta uma influência topoclimática significativa.

A localização da cidade no vale do Paraíba do Sul, entre as serras do Mar e da Mantiqueira, vai caracterizar suas características climáticas no contexto da circulação regional. Pois, as pequenas depressões e frentes podem ter como obstáculo o elevado sistema montanhoso, definido por Conti (1972) como "papel de freio".

As frentes polares, quando estão baixas, não conseguem transpor a Serra do Mar, ocasionando maior precipitação a barlavento, isto é, nas serras do Mar e de Paranapiacaba. A serra da Mantiqueira, só recebe a precipitação quando a frente polar está com altura superior a $1,5 \mathrm{~km}$, mais comum no período do verão, mesmo quando o maior número de incursões das frentes frias seja registrado no período do inverno, porém esta quando atua, provoca normalmente queda de temperatura, mas em um número menor de vezes precipitações (Martins, 1996).

No inverno a massa Tropical Atlântica é predominante, influenciando nas condições de tempo estável. O anticiclone do atlântico sul no inverno se desloca para o continente, o que induz o fenômeno de subsidência, responsável pelo céu azul e sem a presença de chuvas, associado a estabilidade atmosférica e eventos de inversão térmica na cidade.

As alterações ambientais causadas por processos antrópicos tendem a produzir modificações em alguns elementos climáticos, originando fenômenos como o da "Ilha de Calor", responsáveis por temperaturas mais elevadas na área central da cidade, pluviosidades quantitativamente maiores nas áreas urbanizadas, e inversão térmica, associada a períodos de estabilidade atmosférica, principalmente no inverno (MARTINS, 1996). 


\section{A área de estudo}

Foi delimitada a região central da cidade de Juiz de Fora, no qual perpassam as principais vias de circulação de veículos automotores (Av. Barão do Rio Branco, Av. Itamar Franco, Av. Getúlio Vargas, Av. Brasil, Rua Santo Antônio e Av. Olegário Maciel) (Figura 1). Essas vias possuem várias interseções em nível, com frequente presença de sinais de trânsito, apresentando congestionamento nos horários de pico, devendo-se ao aumento da frota veicular e a posição de polo regional que a cidade ocupa atraindo uma população considerável dos arredores que vêm a cidade em busca de uma variedade de serviços.

Em 2015 Juiz de Fora tinha uma frota de 242.273, sendo que destes 183.820 são de automóveis (DENATRAN, 2016). Se considerarmos ainda o número de veículos que transitam pela cidade, mas que pertencem a outros municípios estes números são ainda majorados.

\section{Quantificação e levantamento dos dados relativos ao fluxo de veículos}

\section{a) Volume de Tráfego}

O volume de tráfego consiste no número de veículos que percorre em uma seção da via em uma determinada faixa ou direção, durante um intervalo determinado de tempo (MsShane e Roess apud Oliveira, 2004). Os dados foram levantados em trabalho de campo, no dia 22 de julho de 2014, no período de 06 as 20:00 horas, nos locais Av. Rio Branco (Mergulhão); Av. Brasil, Rua Santo Antônio, Av. Olegário Maciel, Av. Rio Branco (Parque Halfeld) e Av. Independência.

\section{b) Velocidade de tráfego}

Em função do monitoramento e o fornecimento dos dados de fluxo de veículos por parte dos órgãos responsáveis da área de estudo, a velocidade é medida em função: (i) a velocidade média no trecho; (ii) a velocidade medida dos controladores eletrônicos de velocidade na via; (iii) a velocidade permitida na via.

\section{Emissão Veicular}

Segundo Murgel et al. (1987) os fatores de emissão podem ser mensurados através de equipamentos ou estimados por meio de cálculos teóricos. Ainda destaca que devem ser levados em consideração nos cálculos a distância percorrida, tipo de veículo, tamanho, idade, tipo de combustível, situação do tráfego (velocidade). Nesse trabalho vamos estimar os valores de emissão, adotando a metodologia e parâmetros utilizados por Filizola (2005), a adoção desta metodologia está baseada na aplicação do modelo em cidades brasileiras e para carros que aqui trafegam. Filizola (2005) identificou valores referenciais dos níveis de emissão de HC, CO e NOx para veículos leves de ciclo Otto em condições reais de operação (Tabela 2). Neste trabalho vamos estimar apenas o CO e NOx.

Para o cálculo das emissões foi considerado o poluente, número de veículos em um intervalo de tempo (hora e dia). Esse cálculo serve para detectar as condições críticas de emissão e suas relações com a contagem de tráfego. A emissão total calculada na via será expressa em $\mathrm{g}(\mathrm{t}) / \mathrm{km}$ (gramas pelo período de tempo t por km de via). Na estimativa da emissão, FEi é o fator de emissão do poluente i, que pode ser o CO, NOx (o fator de emissão deve considerar à categoria do veículo, tipo de combustível e ano de fabricação).

A quantificação das emissões será calculada aplicando a Equação 1. Na equação, FEi representa o fator de emissão $(\mathrm{g} / \mathrm{km})$ do poluente i e Njt é o fluxo de veículos na via ou ponto de contagem $\mathrm{j}$, em um período de tempo t expresso em veículo/h, veículo/dia. Eijt é a quantidade emitida do poluente i, durante o período de tempo t de estudo de uma determinada via $\mathrm{j}$. fórmula 1.

Para o cálculo das emissões foi considerado cada ponto de contagem, para o CO e NOx se aplicou a

$$
E_{i j t}=F E_{i} \times N_{j t}
$$


Os valores referenciais de emissão de CO, NOx, foram obtidos por Filizola (2005), no qual determinou a emissão veicular em áreas urbanas brasileiras (Tabela 2). Na Tabela 2 são ainda apresentados os cenários para emissão veicular de CO e NOx, proposto por Taco (2006, p. 103) tendo: (i) cenário otimista refere-se a uma situação que considera veículos novos, em bom estado de conservação e boas condições de tráfego; (ii) cenário pessimista considera veículos antigos, em má conservação e condições adversas de circulação nas vias; (iii) cenário normal considera uma situação intermediária, veículos novos e velhos em condições normais de tráfego.

Tabela 2: Criação de cenários de emissão para CO e NOx.

\begin{tabular}{|c|c|c|c|c|c|}
\hline \multirow[b]{2}{*}{ Cenários } & \multicolumn{3}{|c|}{ Características do Cenário } & \multicolumn{2}{|c|}{$\begin{array}{c}\text { Fator de } \\
\text { emissão Filizola } \\
(2005)(\mathrm{g} / \mathrm{km})\end{array}$} \\
\hline & Idade da frota & $\begin{array}{l}\text { Modo de } \\
\text { Condução }\end{array}$ & $\begin{array}{l}\text { Funcionalidade do } \\
\text { Catalisador }\end{array}$ & $\mathrm{CO}$ & $\mathrm{NO}_{\mathrm{x}}$ \\
\hline Pessimista & Antigos & Agressiva & Catalisador antigo & 2,83 & 0,32 \\
\hline Normal & Intermediário & Normal & Catalisador modificado & 2,00 & 0,21 \\
\hline Otimista & Novos & Defensivo & Catalisador novo & 1,16 & 0,10 \\
\hline
\end{tabular}

Fonte: Taco (2006), Filizola (2005).

\section{Espacialização das Informações}

Para trabalhar com a base geográfica, foi utilizado o software ArcView®. A base de dados geográficos foi composta pelo cruzamento do banco de dados dos fluxos de veículos e a base geográfica. $\mathrm{O}$ banco de dados permite a atualização contínua das informações geradas, garantindo maior precisão. Por meio da projeção e sobreposição das informações escolhidas sobre a base geográfica, foram elaborados os mapas temáticos a respeito da poluição veicular. Foram mapeadas as variáveis do ambiente construído (verticalização, arruamento e vias de circulação); altimetria e direção e velocidade dos ventos.

\section{Índice de qualidade do ar}

O Índice de qualidade do Ar (IQA) que será utilizado é o preconizado pela CETESB (2013), no qual, possui uma estrutura que contempla, conforme Resolução CONAMA n ${ }^{\circ}$. 03/90, os seguintes parâmetros: Dióxido de Enxofre, Partículas Totais em Suspensão, Partículas Inaláveis, Fumaça, Monóxido de Carbono, Ozônio e Dióxido de Nitrogênio (Tabela 3). O IQA é calculado através de uma função linear segmentada, onde os pontos de inflexão são os padrões de qualidade do ar. Desta função, que relaciona a concentração do poluente com o valor índice, resulta em número adimensional referido a uma escala com base em padrões de qualidade do ar. Para cada poluente medido é calculado um IQA. Para efeito de divulgação é utilizado o IQ A mais elevado, isto é, a qualidade do ar de uma estação é determinada pelo pior caso. Depois de calculado o valor do índice, o ar recebe uma qualificação, feita conforme a Tabela 4.

Tabela 3: Estrutura do Índice de qualidade do ar (CO e NO2).

\begin{tabular}{lccc}
\hline \multicolumn{1}{c}{ Qualidade } & Índice & $\mathbf{C O}(\mathbf{P P M})$ & $\mathbf{N O}_{\mathbf{2}}\left(\boldsymbol{\mu g} / \mathbf{m}^{\mathbf{3}}\right)$ \\
\hline Boa & $0-50$ & $0-9$ & $0-200$ \\
Regular & $51-100$ & $9-11$ & $>200-240$ \\
Inadequada & $101-199$ & $11-13$ & $>240-320$ \\
Má & $200-299$ & $13-15$ & $>320-1130$ \\
Péssima & $>300$ & $>15$ & $>1130$ \\
\hline
\end{tabular}

Fonte: CETESB, 2013 
Tabela 4: Índices de Qualidade do ar e os efeitos à saúde.

\begin{tabular}{lcl}
\hline \multicolumn{1}{c}{ Qualidade } & Índice & \multicolumn{1}{c}{ Efeitos à Saúde } \\
\hline Boa & $0-40$ & \\
\hline Moderada & $41-80$ & $\begin{array}{l}\text { Pessoas de grupos sensíveis (crianças, idosos e pessoas com doenças } \\
\text { respiratórias e cardíacas), podem apresentar sintomas como tosse } \\
\text { seca e cansaço. A população, em geral, não é afetada. }\end{array}$ \\
\hline Ruim & $81-120$ & $\begin{array}{l}\text { Toda a população pode apresentar sintomas como tosse seca, } \\
\text { cansaço, ardor nos olhos, nariz e garganta. Pessoas de grupos } \\
\text { sensíveis (crianças, idosos e pessoas com doenças respiratórias e } \\
\text { cardíacas). }\end{array}$ \\
\hline Muito Ruim & $121-200$ & $\begin{array}{l}\text { Toda a população pode apresentar agravamento dos sintomas como } \\
\text { tosse seca, cansaço, ardor nos olhos, nariz e garganta e ainda } \\
\text { apresentar falta de ar e respiração ofegante. Efeitos ainda mais graves } \\
\text { à saúde de grupos sensíveis (crianças, idosos e pessoas com doenças } \\
\text { respiratórias e cardíacas). }\end{array}$ \\
\hline Péssima & $\begin{array}{l}\text { Toda a população pode apresentar sérios riscos de manifestações de } \\
\text { doenças respiratórias e cardiovasculares. Aumento de mortes } \\
\text { prematuras em pessoas de grupos sensíveis. }\end{array}$ \\
\hline
\end{tabular}

Fonte: CETESB, 2013.

Para obtermos um padrão de referência, entre os dados estimados de $\mathrm{CO}$ e NOx, e o que estes valores representavam em termos de qualidade do ar, foi idealizado um modelo, no qual as condições reais, se assemelhariam às condições modelares, para isso, considerou-se condições atmosféricas de 250, pressão atmosférica padrão e estabilidade atmosférica, no qual os ventos estariam muito próximos a calmaria ou principalmente ausentes.

Como as vias estudadas, excetuando a Av. Brasil, todas as demais (Av. Barão do Rio Branco, Av. Olegário Maciel, Av. Independência e Rua Santo Antônio) possuem em ambos os lados grande verticalização, prevalecendo prédios com mais de 5 andares, simulou-se o que ocorreria com a atmosfera (Figura 2), em diferentes alturas, que vai desde logo acima do ponto emissor, até apresentar maior dissipação dos gases, representaria em termos de qualidade do ar. Sendo assim, foi utilizado o modelo, no qual a atmosfera foi representada por um paralelepípedo onde possui o comprimento de $1 \mathrm{Km}$ (equação 1), a largura respectiva entre os prédios, que corresponde na largura da via com a adição do tamanho das calçadas e canteiros de separação de vias e a altura. Desta forma, para diferentes alturas vamos possuir diferentes valores de volume da atmosfera e assim uma diferente capacidade de dispersão do poluente, o que implica em quanto maior a altura maior a dispersão e melhor a qualidade do ar.

Logo, passa-se do pressuposto que sob condições de estabilidade atmosférica, a movimentação turbulenta do ar diminuiria, o que levaria a maior concentração dos gases emitidos próximo a fonte emissora, e como as ruas são fechadas em ambos os lados por paredes (verticalização provocada por prédios elevados), diminuiria a dissipação para os lados, restando apenas o movimento ascendente. Desta forma, este modelo calcula o quanto a concentração aumenta na atmosfera, quanto mais próximo da fonte emissora e tende a se dissipar quanto mais afastada dela (em termos de altura na atmosfera), uma vez que os prédios impedem sua dissipação para os lados.

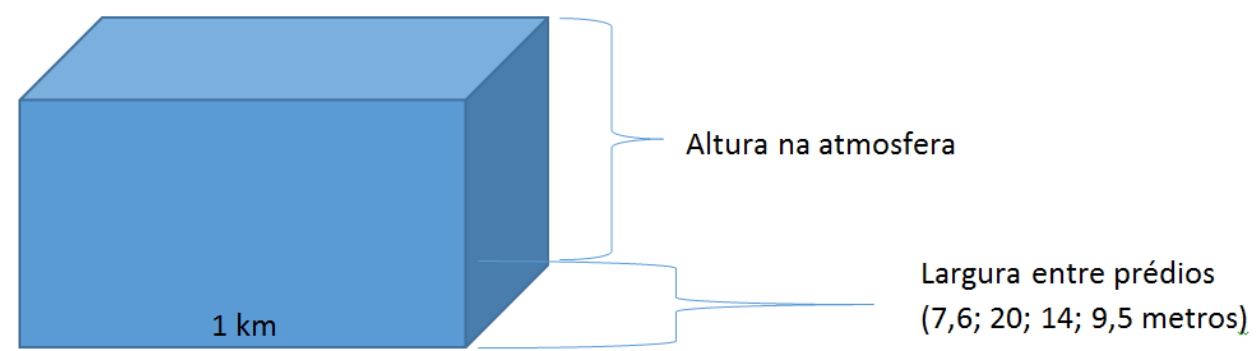

Figura 2: Representação do modelo de simulação das condições de qualidade do ar. 


\section{RESULTADOS}

Os resultados serão apresentados em função do poluente e dos horários de medição dos fluxos de automóveis, no qual foram considerados os horários com maior fluxo de automóveis e o total de automóveis dia:

\section{Horários de pico (7:00-8:00h / 13:00-14:00 / 17:00-18:00)}

O maior volume de veículos está associado à principal via de deslocamento na região central de Juiz de Fora, sendo esta a Av. Barão do Rio Branco, que possui um sentido Norte/Sul, no qual convergem para ela todo o fluxo de veículos que desejam atingir a região central da cidade. O volume máximo de veículos no horário de 17:00-18:00. Este volume de veículos repercutirá na emissão de $\mathrm{CO}$, que neste horário terá o maior pico de emissão, sendo estimado para o cenário normal de $10080 \mathrm{~g} / \mathrm{h}$ por km (Figura 3). Assim como de NOx, apresentando um valor máximo estimado para o cenário normal de 1054,4 g/h por km (Figura 4). Cabe ainda ressaltar, a presença de congestionamento nos horários de pico nesta via, o que reduz sobremaneira a velocidade média da pista $(50 \mathrm{~km} / \mathrm{h})$, intensificando a liberação de poluentes.

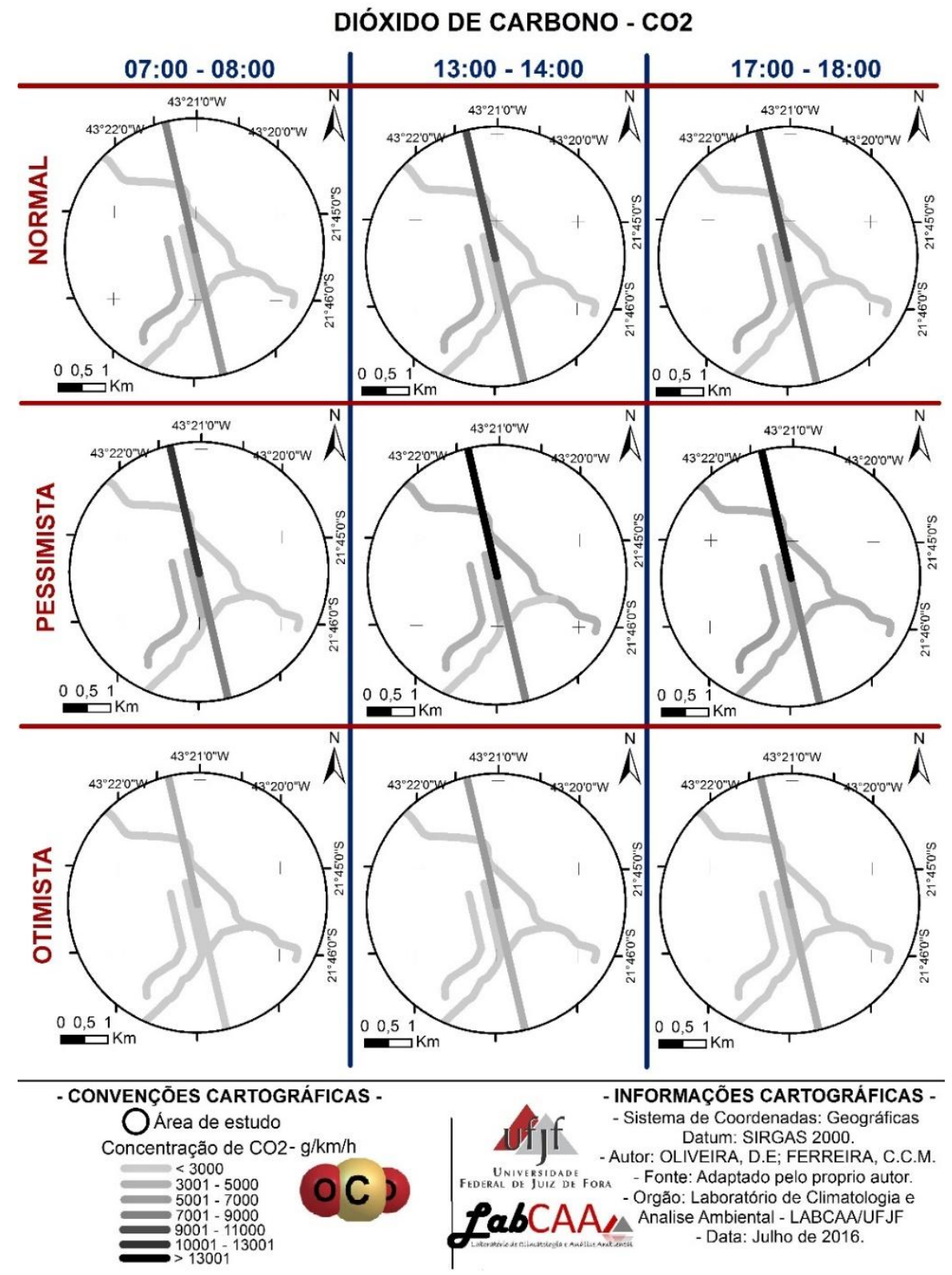

Figura 3: Espacialização do Monóxido de Carbono, apresentando os cenários normal, pessimista e otimista para as vias principais da área central da cidade de Juiz de Fora-MG. 


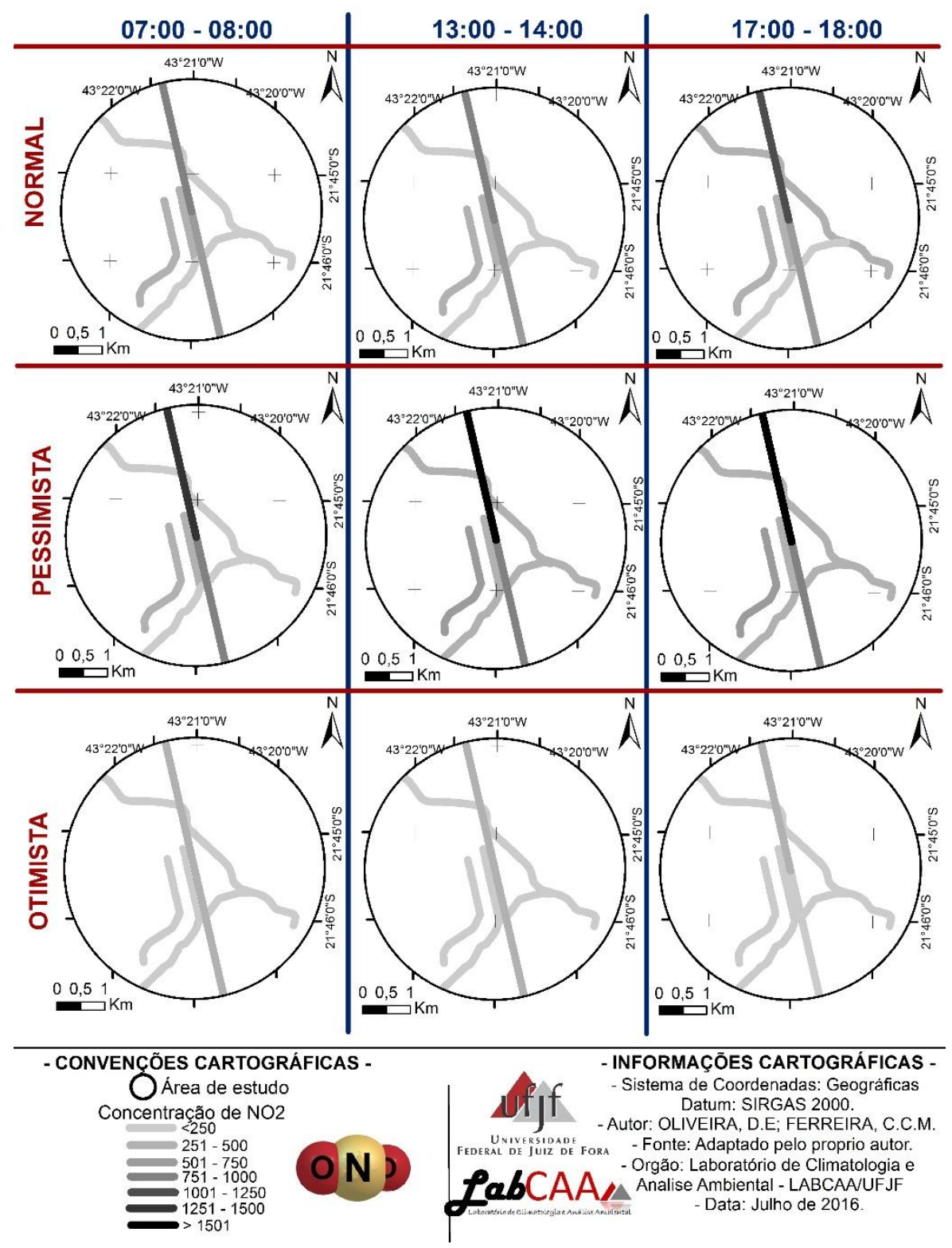

Figura 4: Espacialização do Dióxido de Nitrogênio, apresentando os cenários normal, pessimista e otimista para as vias principais da área central da cidade de Juiz de Fora-MG.

Quando comparamos com os demais mapas, verificamos que o sentido dos ventos predominantes na cidade é norte (Figura 5), o que poderia influenciar no processo de dispersão destes poluentes, porém nos dados de verticalização (Figura 5), detectamos que ao longo desta avenida temos uma predominância de prédios acima de 10 andares, o que provoca a canalização dos ventos e retenção da poluição ali gerada sobre a própria região, o que poderia levar a uma maior concentração destes poluentes. Kumar et al. (2015) destaca que há evidências de que quem vive na vizinhança de vias com alto volume de tráfego apresenta maiores danos à sua saúde respiratória.

As demais vias são rotas alternativas à Av. Barão do rio Branco, e que também vêm apresentando grande fluxo de veículos, sendo estas a Av. Olegário Maciel e a Rua Santo Antônio, respectivamente tiveram o volume máximo de veículos no horário de 17:00-18:00. Sendo que a emissão máxima para CO foi de 3744 e 3072 g/h/km e de NOx de 393 e 322,5 g/h/km (Figuras 3 e 4). Nos horários de Pico a av. Olegário Maciel apresenta congestionamentos, principalmente atrelados aos horários de início e térmico das atividades escolares. Cabe ressaltar que a Rua Santo Antônio é mais estreita e possui alta verticalização em ambos os lados da via, o que represa a poluição ali gerada, os ventos são de baixa intensidade, em função dos obstáculos representados pela intensa verticalização presente nesta área da cidade, o que pode influenciar na saúde da população ali residente (Figura 5). 


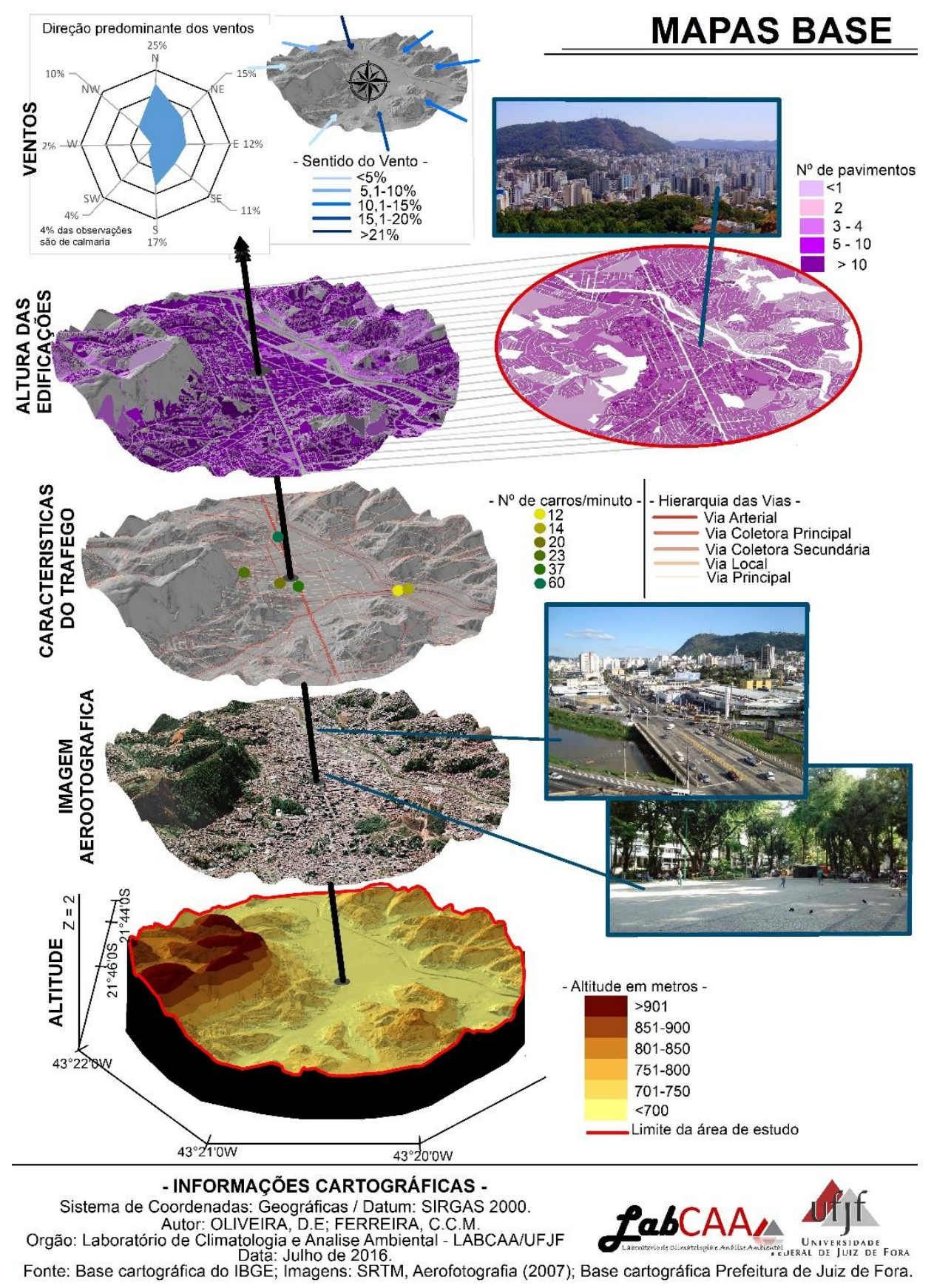

Figura 5: Mapas temáticos da região em estudo (Altitude, imagem aerofotogramétrica, características do tráfego de veículos automotores, altura das edificações e direção e velocidade dos ventos.

A Av. Itamar Franco é uma via que cruza a Av. Barão do Rio Branco e possui um fluxo de veículos ligado à conexão entre diferentes bairros da cidade com a área central, além de ser influenciado pela presença de dois grandes colégios e o fluxo oriundo da entrada e saída de escolares (Figura 1). Apresenta um volume de veículos menor que as demais vias analisadas, com 872 veículos/h e uma taxa máxima de emissão de CO estimada em $2160 \mathrm{~g} / \mathrm{h} / \mathrm{km}$ e de NOx de 226,8 (Figuras 3 e 4). A Av. Itamar Franco, também é uma via com uma alta presença de verticalização em ambos os lados da via, possui um sentido leste/oeste, o que faz dela uma via com baixa velocidade dos ventos e quando ali presentes são canalizados.

A Av. Brasil é uma importante via de interligação da zona norte, central e sudeste da cidade, com um fluxo intenso de veículos pesados, pois faz a interligação da BR $262 \mathrm{com}$ a BR040. Esta avenida margeia o rio principal que corta a cidade, o que dá a ela maior capacidade de dispersão dos poluentes ali gerados. Como está localizada em uma área mais aberta, possui uma maior velocidade de ventos o que possibilita maior dispersão dos poluentes. 
Lima, et al. (2003) em um estudo sobre poluição veicular em Juiz de Fora, mais precisamente no Bairro Manoel Honório, no qual a Av. Brasil passa e está localizada a estação de PM10, destacam a relação do volume de veículos com a concentração de PM10, nesta avenida, evidenciando o papel da atmosfera nos processos de dispersão/concentração e a relação dos horários de pico com os períodos de maior concentração de PM10.

Com relação aos valores encontrados, temos um total máximo de veículos/hora no horário de 17:0018:00, sendo que as taxas estimadas para um Cenário Normal de CO foram de $2400 \mathrm{~g} / \mathrm{h} / \mathrm{km}$ e de NOx de 252 $\mathrm{g} / \mathrm{h} / \mathrm{km}$ (Figura 3 e 4).

Destaca-se que segundo a fórmula aplicada para estimativa de $\mathrm{CO}$ e NOx liberada por veículos automotores é diretamente proporcional ao número de veículos na via, logo, a redução da velocidade e congestionamentos e constantes reduções e acelerações, ocasionaria um maior número de veículos ligados e liberando gases e consequentemente acarretaria em uma maior poluição veicular.

Tentando estabelecer um parâmetro que nos permitisse comparar os dados estimados de CO e NOx, adotou-se o índice de Qualidade do Ar (CETESB, 2013). Seguindo a metodologia já destacada, permitiu-se verificar que em função da alta verticalização presente nas vias estudadas, os gases tendem a ficar mais concentrados próximos a fonte emissora e mais dissipados quanto mais afastada dela, além disso destaca-se que as ruas com menor largura e com alto fluxo de veículos, foram as que apresentaram maiores concentrações e consequentemente pior índice, como foi o encontrado nas ruas Santo Antônio e Olegário Maciel. As ruas de maiores dimensões, mesmo tendo um alto fluxo de veículos, tiveram um comportamento melhor, como a Av. Rio Branco e Independência. Logo a capacidade de concentração e dispersão da atmosfera, a partir da fonte emissora, também dependerá do ambiente construído, que em muito influi na capacidade de dispersão, pois redireciona ventos ou mesmo cria campos com a sua ausência, dificultando, portanto, a dispersão dos poluentes (Tabelas 5 e 6).

Tabela 5: Índice de qualidade do ar (CETESB, 2013) e a relação do índice com a faixa altimétrica de interferência do monóxido de carbono.

\begin{tabular}{lccccc}
\hline Qualidade & Índice & \multicolumn{4}{c}{ Vias de circulação de veículos automotores } \\
\cline { 2 - 6 } & & $\begin{array}{c}\text { Santo Antônio } \\
(\mathbf{m})\end{array}$ & $\begin{array}{c}\text { Rio Branco } \\
(\mathbf{m})\end{array}$ & $\begin{array}{c}\text { Itamar Franco } \\
(\mathbf{m})\end{array}$ & $\begin{array}{c}\text { Olegário Maciel } \\
(\mathbf{m})\end{array}$ \\
\hline Boa & $0-50$ & $>32,32$ & $>38,27$ & $>12,09$ & $>31,05$ \\
\hline Moderada & $51-100$ & $26,45-32,32$ & $31,31-38,27$ & $9,89-12,09$ & $25,40-31,05$ \\
\hline Ruim & $101-199$ & $22,38-26,45$ & $26,49-31,31$ & $8,37-9,89$ & $21,49-25,40$ \\
\hline Muito Ruim & $200-299$ & $19,39-22,38$ & $22,96-26,49$ & $7,25-8,37$ & $18,63-21,49$ \\
\hline Péssima & $>300$ & $<19,39$ & $<22,96$ & $<7,25$ & $<18,63$ \\
\hline
\end{tabular}

Tabela 6: Índice de qualidade do ar (CETESB, 2013) e a relação do índice com a faixa altimétrica de interferência do Dióxido de Nitrogênio.

\begin{tabular}{lccccc}
\hline Qualidade & Índice & \multicolumn{4}{c}{ Vias de circulação de veículos automotores } \\
\cline { 3 - 6 } & & $\begin{array}{c}\text { Santo Antônio } \\
(\mathbf{m})\end{array}$ & $\begin{array}{c}\text { Rio Branco } \\
(\mathbf{m})\end{array}$ & $\begin{array}{c}\text { Itamar } \\
\text { Franco } \\
(\mathbf{m})\end{array}$ & $\begin{array}{c}\text { Olegário Maciel } \\
(\mathbf{m})\end{array}$ \\
\hline Boa & $0-50$ & $>174,91$ & $>207,06$ & $>65,4$ & $>168$ \\
\hline Moderada & $51-100$ & $145,76-174,91$ & $172,55-207,06$ & $54,5-65,4$ & $140-168$ \\
\hline Ruim & $101-199$ & $109,32-145,76$ & $129,41-172,55$ & $40,88-$ & $105-140$ \\
\hline Muito Ruim & $200-299$ & $30,96-109,32$ & $36,65-129,41$ & $11,58-$ & $29,73-105$ \\
\hline Péssima & $>300$ & $<30,96$ & $<36,65$ & $<11,58$ & $<29,73$ \\
\hline
\end{tabular}




\section{CONCLUSÕES}

Destaca-se uma premente necessidade de estudos específicos sobre poluição atmosférica em cidades médias, que a muito vêm enfrentando problemas decorrentes da poluição do ar, principalmente no período do inverno, quando a atmosfera apresenta períodos de maior estabilidade e consequente concentração de poluentes.

Como o monitoramento da poluição atmosférica não é realizado na cidade de Juiz de Fora, com equipamentos que permitiriam a medição e consequente controle da mesma, optamos em trabalhar com os valores referenciais de emissão veicular de CO e NOx, obtidos por Filizola (2005), que já são aplicados em várias cidades no Brasil.

A aplicação dos valores referenciais de emissão veicular permitiu estimar a emissão do CO e NOx nas principais vias do centro da Cidade de Juiz de Fora-MG, simulando as condições reais de operação dos fluxos de veículos. Além disso, foi possível espacializar e comparar os dados estimados com o ambiente construído, a dinâmica dos ventos e a disposição da área de estudo no sítio urbano.

Segundo o modelo de estimativa de emissões veiculares de CO e NOx foi possível detectar uma relação imediata entre o fluxo de veículos automotores e a emissão, além disso ao estabelecermos uma análise entre os dados estimados e o índice de qualidade do ar (CETESB, 2013), verificou-se uma forte relação da concentração/dissipação com as características das ruas e avenidas, como verticalização e largura da via, o que influenciaria sobremaneira a capacidade de dispersão do gás a partir da fonte emissora. Mostrando, portanto, um agravamento da qualidade do ar em vias mais estreitas e com alto fluxo de automóveis.

Enfatizamos ainda que seria importante a cidade conhecer os pontos de maior poluição, uma vez que esta implica na qualidade de vida da população citadina e principalmente no agravamento nos quadros de saúde da população. $O$ controle da emissão de gases poluentes permitiria que tivéssemos um menor número de pacientes nos postos e hospitais em função principalmente do agravamento no quadro de doenças respiratórias.

\section{REFERÊNCIAS}

AZUAGA, D. Danos ambientais causados por veículos leves no Brasil. 2000. Dissertação (Mestrado Engenharia) - COPPE, Universidade Federal do Rio de Janeiro, Rio de Janeiro, 2000.

BAIRD, C. Química Ambiental. Tradução Maria Angeles Lobo Recio; Luiz Carlos Marques Carrera. 2. ed. Porto Alegre: Bookman, 2002.

BATTERMAN, S.; CHAMBLISS, S.; ISAKOV, V. Spatial resolution requirements for traffic-related air pollutant exposure evaluations. Atmospheric Environment, v.94, p.518-528, sep.2014.

BRASIL. Ministério do Meio Ambiente. Inventário Nacional de Emissões Atmosféricas por Veículos Automotores Rodoviários 2013 ano-base 2012. Brasília, 2000. Disponível em: <http://www.mma.gov.br/images/arquivo/80060/Inventario_de_Emissoes_por_Veiculos_Rodoviarios_201 3.pdf>. Acesso em: 26 mai. 2014.

BRUCKMAN, L.; DICKSON, R. J. e WILKOSEN, J. G. (1992). The Use of GIS Software in the Development of Emissions Inventories and Emission Modeling. In: Proceedings of the Air and Waste Management Association, Pittsberg, PA. USA.

CENTRAL POLLUTION CONTROL BOARD (CPCB) Annual Report 2011-2012. Dehli: Central Pollution Control Board, 2012

CETESB. Companhia de Tecnologia e Saneamento Ambiental. Plano de Controle de Poluição Veicular do Estado de São Paulo. São Paulo: CETESB, 2011. Disponível em: <http://www.cetesb.sp.gov.br/userfiles/file/noticias/pcpv.pdf>. Acesso em: 23 abr. 2013.

CETESB. Companhia de Tecnologia e Saneamento Ambiental. Índice de qualidade do ar. São Paulo. São Paulo: CETESB, 2013. Disponível em: <http://ar.cetesb.sp.gov.br/padroes-de-qualidade-do-ar/> Acesso em: 20 abr. 2016. 
CHELANI A.B., RAO C. C.V., PHADKE K.M., HASAN M.Z. S. Formation of an Air Quality Index in India. Intern. J. Environ. Studies, v. 59, n.3, p. 331-342, 2001.

CONTI, J.B. A circulação secundária e o efeito orográfico na gênese regional das chuvas. São Paulo: FFLCH/USP, 1972.

CRABBE H., HAMILTON R., MACHIN N. Using GIS and Dispersion Modelling Tools to Assess the Effect of the Environment on Health.Transactions in GIS, v.4, n.3, p.235-244, 2000.

CRUZ, M. M. L. Avaliação dos impactos de restrições ao trânsito de veículos. 2006. Dissertação (Mestrado em Transporte) - Engenharia Civil, Universidade Estadual de Campinas, Campinas, 2006.

BRASIL. Departamento Nacional de Trânsito-DENATRAN. Tráfego e Meio Ambiente. Brasília, 1980.

BRASIL. Departamento Nacional de Trânsito - DENATRAN. Frota de Veículos. Brasília, 2016. Disponível em: 〈http://www.denatran.gov.br/frota.htm>. Acesso em: 01 abr. 2016.

DUTRA, E. G. Metodologia Teórico-Experimental para Determinação dos Parâmetros Básicos para Elaboração de Inventários de Emissão de Veículos Leves do Ciclo Otto. 2007. 166f. Tese (Doutorado em Calor e Fluidos) - Engenharia Mecânica, Universidade Federal de Minas Gerais, Belo Horizonte, 2007.

ECOSOFT consultoria e softwares ambientais ltda. Inventário de fontes de poluentes atmosféricos, estudo de dispersão atmosférico e projeto de rede otimizada de monitoramento atmosférico para a região metropolitana de Belo Horizonte - Contagem - Betim. Belo Horizonte, 2003. Apud FUNDAÇÃO ESTADUAL DE MEIO AMBIENTE. Plano de Controle de Poluição Veicular de Minas Gerais 2014-2017. Belo Horizonte: $\quad 2014.2$ DEAM, em: <http://www.feam.br/images/stories/2015/QUALIDADE_AR/180815-pcpv\%20para\%20web.pdf.>. Acesso em: 10 abr. 2016.

FERRAZ, C; MOTTA, R. S. O Controle da Poluição. Rio de Janeiro, 2008. Disponível em: http://eqe.com.br/eco-co2. Acesso em: 08 de Mai. de 2008.

FERREIRA, C.C.M. Modelo para análise das variáveis de cobertura da terra e a identificação de microclimas, em centros urbanos. Revista Brasileira de Climatologia. v.14, n.10, p. 50-75, Jan/jul. 2014.

FILIZOLA, I. M. (2005). Identificação de valores referenciais do nível de emissão de gases veiculares automotores leves do ciclo Otto. Dissertação (Mestrado Engenharia Civil) - Departamento de Engenharia Civil e Ambiental, Universidade de Brasília, Brasília, 2005.

FISHER J. B., KELLY M., ROMM J.. 2005. Scales of environmental Justice: Combining GIS and Spatial analysis for air toxics in West Oakland, Elsevier, Health e Place, California, v.12, p.701-714, 2005.

FUNDAÇÃO ESTADUAL DE MEIO AMBIENTE. Plano de Controle de Poluição Veicular de Minas Gerais 2014-2017. FEAM, Belo Horizonte, 2014.

GUALTIERI, G.; TARTAGLIA, M. (1998). Predicting Urban Traffic Air Pollution: A GIS Framework. Transportation Research, Part D, v. 3, n5, p. 329-336, 1998.

GOODWIN J.W.L., SALWAY A.D., DORES C.J., PASSANT N.R., KING K.R., COLEMAN P. J., HOBSON M.M., PYE S.T. E WATTERSON J.D. UK emissions of air pollutants 1970-1999. Report AEAT/ENV/R/0798. EPG 1/1/171. AEA Tecnology, NETCEN, Culham. 2001

HUO, H., ZHANG, Q., HE, K., YAO, Z., WANG, X., ZHENG B., STREETS, D. G., WANG, Q., DING, Y. Modeling vehicle emissions in different types of Chinese cities: Importance of vehicle fleet and local features. Environmental Pollution, v.159, p. 2954-2960, 2011.

JENSEN, S. S.; BERTOWICZ, R; HANSEN, H. S. e HERTEL, O. A Danish Decision-Support GIS Tool for Management of Urban Air Quality and Human Expusures. Transportation Research, Part D, v.6, p. 229241, 2001.

JOSHI P. C, SEMWAL M. Distribution of air pollutants in ambient air of district Haridwar (Uttarakhand), India: A case study after establishment of State Industrial Development Corporation. International Journal of Environmental Sciences. v.2, n1, 2010.

KOUSA, A.; KUKKONEN, J.; KARPPINEN, A.; AARINO, P. e KOSKENTALO, T. (2002). A Model for Evaluating the Population Exposure to Ambient Air Pollution in an Urban Area. Atmospheric Environment, v.36, p. $2109-2119,2002$ 
KUMAR, A.; KUMAR, R.M.; SINGH, S.K. GIS Application in Urban Traffic Air Pollution Exposure Study: A Research Review. Suan Sunandha Science and Technology Journal, v.2, n.1, p. 25-37, Jan. 2015.

LIMA, H.F.P; OLIVEIRA, N.B.; FERREIRA, C.C.M.; MARTINS, L.A. Estudos da Poluição veicular de Juiz de Fora-MG. (2003). In: Anais: X Simpósio Brasileiro de Geografia Física Aplicada, 2003. Disponível em: http://www.cibergeo.org/XSBGFA/eixo3/3.4/291/291.htm. Acesso em: 06 jun. 2016.

MAANTAY J.A., TU J., MAROKO A. R.2008. International Journal of Environmental Health Research, v.19, n.1, p.59-79, 2008.

MARQUEZ L. O., SMITH N. C. A framework for linking urban form and air quality.1999. Elsevier Ltd. Environmental Modelling e Software, v.14, p.541-548, 1999.

MARTINS, L. A. A Temperatura do Ar em Juiz de Fora - MG: Influência do Sítio e da Estrutura Urbana. 1996.168p. Dissertação (Mestrado em Geografia) - Departamento de Geografia, Instituto de Geociências e Ciências Exatas, UNESP - Rio Claro, Rio Claro, 1996.

MARTINS, J. A. e SANTOS, M. P. S. (1998). O Índice Topológico como Parâmetro Urbanístico para Monitorar a Capacidade Ambiental de Vias Urbanas. XII Congresso de Pesquisa e Ensino em Transportes - ANPET, Fortaleza, v.1, p. 413-425, 1998.

MARTINS, J. A. (1999). Qualidade ambiental urbana para todos. Revista CREA RJ, Rio de Janeiro, n.24, maio/jun 1999.

MATEJICEK L. Spatial modeling of air pollution in urban areas with GIS: a case study on integrated database development. Advances in Geosciences, v.4, p.63-68, 2005

MEDINA, I. C.; SCHATTANEK, G. e NICHOLS, F. JR. (1994). A Framework for Integrating Information Systems in Air Quality Analysis. In: Proceedings of URISA 1994, 32a Annual Conference, Milwaukee, WI (EUA), p. 339. 1994.

MONTEIRO, A. G. Estratégia de Redução de Emissões de Poluentes no Setor de Transportes por Meio de Substituição Modal na Região Metropolitana de São Paulo. Tese (Doutorado Engenharia) - PPE, universidade Federal do rio de Janeiro, Rio de Janeiro, 1998. Disponível em: <http://www.ppe.ufrj.br/ppe/production/tesis/amonteiro.pdf>. Acesso em: 02 Jun. 2008.

MONTEIRO, C. A. F. Teoria e clima urbano. 1976. Tese (Livre Docência)-Universidade de São Paulo, São Paulo, 1976.

MURGEL, E. M.; SZWARC, A.; SANTOS, M. D.; BRANCO, G. M. e CARVALHO, H. Inventário de Emissão Veicular: Metodologia de Cálculo, Revista de Engenharia Sanitária, v.26, n.3, 1987.

OLIVEIRA, M. V. T. (2004). A Natureza dos Padrões de Variação Espaço-Temporal do Volume Veicular em Ambiente Urbano: Estudo de Caso em Fortaleza. Dissertação (Mestrado em Engenharia de Transporte) - Programa de Mestrado em Engenharia de Transportes, Centro de Tecnologia, Universidade Federal do Ceará, Fortaleza, 2004.

PANDEY, M.; VARUN, S.R.C.; VAISHYA, A.K.S. Analysis e Application of GIS Based Air Quality Monitoring- State of Art. In: International Journal of Engineering Research e Technology (IJERT), v.2, n.12, p. 3788-3796. Dec. 2013.

PJF. Plano Diretor de Juiz de Fora. Juiz de Fora: Concorde, 1996

RIBEIRO, R. A. e DOMINGUEZ, E. M. (2005). Distribuição espacial da poluição atmosférica: estudo de uma rede de transporte público de Porto Alegre. Pôster - 182. Anais do Congresso Luso Brasileiro para o Planejamento Urbano Regional Integrado Sustentável - PLURIS 2005. São Carlos, 2005. CD-ROM.

SALA, J. F. Valoração dos Custos Ambientais Relacionados à Saúde - Estudo de Caso: Setor de Transportes da Cidade de São Paulo. 1999. Dissertação (Mestrado Engenharia) - COPPE, Universidade Federal do Rio de Janeiro, Rio de Janeiro, 1999.

SOULEYRETTE, R. R.; SATHISAN, S.K.; JAMES, D. E. e LIM, S. (c1992). GIS for transportation and air quality analysis. Proceedings of the National conference on Transportation Planning and Air Quality. ASCE, New York (USA), p. 182 -194, 1992.

SUTANTO, S.; ERNI, S. T. Study on correlation between motor vehicle emission and public health, Eastern Asia Society for Transportation Studies, v.5, p.1841-1856, 2005. 
TACO, G.B.G. Desenvolvimento de uma metodologia para identificar espacialmente os níveis de emissão de gases derivados de veículos automotores nas áreas urbanas. 2006. 156p. Dissertação (Mestrado em Transportes) - departamento de Engenharia Civil e Ambiental, UNB, Brasília, 2006.

USA. United State Environmental Protection Agency. Air Quality Index (AQI) - A Guide to Air Quality and Your Health. 2010. Disponível em: <http://www.epa.gov/2010>. Acesso em: 20 mai 2016.

WHITELEGG, J.; HAQ, G. The global transport problem: some issues but a diferente Place (in John World Transport, Policy and Practice). London, Earth scan publications limited, 2003. 